\title{
U.S. Dollar Asymmetry And Exchange Rate Volatility
}

Dr. Nikiforos T. Laopodis, Economics, Villa Julie College

\begin{abstract}
The paper explores the stochastic behavior of six exchange rates- three EMS and three non-EMS -during the U.S. dollar appreciation (before 1985) and depreciation (after 1985) using the Exponential GARCH-M model. The results showed that high volatility in all rates was present before 1985, increased dramatically thereafter, and decreased later for the non-EMS rates. In general, U.S. dollar depreciations increased the volatility more than appreciations did for the French franc, the Italian lira, and the German mark.
\end{abstract}

\section{Introduction}

I $t$ has been well established by now that increased exchange rate volatility during the last decade or so is harmful to economic welfare due to its adverse effects on international trade and investment. Concern over volatility gave rise to numerous studies in an attempt to explain and model it using the now-standard methodology of Autoregressive Conditional Heteroskedastic (ARCH) model set forth by Engle (1982). Their common conclusion was the rejection of the stationarity assumption in the second moment of the exchange rate distributions, which implies that volatility must be modeled as conditionally heteroskedastic. ${ }^{1}$ Several other studies employed linear-type ARCH models (for a survey see Bollerslev, Chou, and Croner, 1992), to further investigate volatility dynamics and spillovers across markets. $^{2}$ An extended version of the ARCH model, called Generalized ARCH, was introduced by Bollerslev (1986) and nests a variety of parametric specifications to further examine the stochastic behavior of exchange rates.

Interestingly, despite the rich research on asymmetric volatility of stock returns ${ }^{3}$, studies, with the exception of Koutmos (1994), examined exchange rate volatility ignoring asymmetry. Nelson (1991), in particular, criticized ARCH models for being restrictive in modeling the conditional variance, specified as a linear function of past innovations and conditional variances, and proposed a model, called Exponential GARCH, that permits shocks to influence the conditional variance in an asymmetric fashion. Many authors, e.g., Pagan and Schwert (1990), Koutmos (1992), used this model and attested to its superiority with respect to the asymmetric nature of volatility.

This paper sheds light to the behavior of volatility of six major exchange rates with respect to the U.S. dollar, taking into account cycles of asymmetry in the dollar's past. Specifically, its volatility pattern before 1985 when the dollar was strong, and after 1985 when it was weak, will be examined. Because the U.S. dollar is the leading reserve and intervention currency, the extent to which other major exchange rates respond to its asymmetric behavior should be of significance to world investors and traders. The study employs Nelson's above-mentioned specification and was chosen on the basis of its ability to accommodate asymmetries such as appreciations and depreciations. Furthermore, the model is capable of addressing issues regarding the predictability of future volatility, and whether positive or negative shocks influence volatility equally. 
The remainder of the paper obeys the following order: section II lays out briefly the model to be estimated; the data, some preliminary statistical results and the model's major empirical findings are contained in section III; section IV offers a summary and some concluding remarks and section $\mathrm{V}$ provides some suggestions for future research.

\section{The Exponential Garch-M Model}

The Exponential Generalized Autoregressive Conditional Heteroskedastic in-Mean model (EGARCH-M) of order $\mathrm{p}$ and $\mathrm{q}$ is specified as follows:

$S_{\mathrm{it}} \mid \Omega_{\mathrm{t}-1} \sim \mathrm{N}\left\{\mu_{\mathrm{t}}, \sigma_{\mathrm{t}}^{2}\right\}$

$\mu_{\mathrm{t}}=\beta_{1}+\beta_{2} \mathrm{~S}_{\mathrm{t}-\mathrm{s}}+\beta_{3} \ln \left(\sigma_{\mathrm{t}}\right)$

$\varepsilon_{\mathrm{t}}=\mathrm{S}_{\mathrm{t}}-\mu_{\mathrm{t}}$

$\sigma_{\mathrm{t}}^{2}=\exp \left\{\alpha_{0}+\Sigma_{\mathrm{t}=1}^{\mathrm{p}} \alpha_{1} \mathrm{~h}\left(\mathrm{z}_{\mathrm{t}-\mathrm{p}}\right)+\Sigma_{\mathrm{t}=1}^{\mathrm{q}} \mathrm{a}_{2} \ln \right.$ $\left.\left(\sigma_{t-q}^{2}\right)\right\}$

$L(\Xi)=-(1 / 2)\left\{\ln \left(\sigma_{t}^{2}\right)+\varepsilon_{t}^{2} / \sigma_{t}^{2}\right\}$

Equation (1) describes the logarithm of the percentage changes of exchange rate $i$ at time $t$, $S_{\text {it }}$, where $\mu_{\mathrm{t}}$ and $\sigma_{\mathrm{t}}^{2}$ denote conditional mean and the conditional variance of $S_{\text {it }}$ based on the information set $\Omega_{\mathrm{t}-1}$. The lagged term in (2) allows for possible autocorrelation and would validate or not the martingale hypothesis, according to which future rate changes are not predictable from past information. Coefficient $\beta_{3}$ measures the EGARCH-M effect (or risk premium). The conditional variance (4) describes an exponential function of past conditional variances, $\alpha_{2}$, and past values of $z_{t}$, where $z_{t}=\varepsilon_{t} / \sigma_{t}$ is an iid process with mean, $\mathrm{E}\left(\mathrm{z}_{\mathrm{t}} \mid \Omega_{\mathrm{t}-1}\right)$, zero and variance, $\operatorname{Var}\left(\mathrm{z}_{\mathrm{t}} \mid \Omega_{\mathrm{t}-1}\right)$, one for all $\mathrm{t}$. The function $\mathrm{h}(\mathrm{z})$ of the standardized residuals is expressed as $h\left(z_{t}\right)=\left[\left|z_{t}\right|-E\left(\left|z_{t}\right|\right)+\gamma z_{t}\right]$ where $E\left(\left|z_{t}\right|\right)=\sqrt{ }(2 / \pi)$ and allows for the measurement of any asymmetric impact (effect) of shocks on volatility. The term $\left|z_{t}\right|-E\left(\left|z_{t}\right|\right)$ captures the magnitude effect, whereas $\gamma z_{t}$ represents the sign effect of a shock. If, for example, $\gamma<0$ then volatility will increase more by a negative shock than by a positive shock. Naturally, if $\gamma=0$ then a symmetric impact on volatility in the presence of shocks of equal magnitude is implied.

The last term in (4), $\Sigma^{\mathrm{q}} \alpha_{2}$, measures the persistence of volatility and if it is less than one, as required for the unconditional variance, $\exp \left(\alpha_{0} / 1\right.$ $\left.\Sigma^{\mathrm{q}} \alpha_{2}\right)$, to exist then the conditional variance is stationary. Finally, (5) describes the sample likelihood function of the rate changes and, given initial values for $\varepsilon$ and $\sigma$, the parameter vector $\Xi$ will be estimated using a nonlinear maximization method (based on the Berndt et al. (1974) algorithm).

\section{Empirical Results}

The sample contains the daily U.S. dollar spot exchange rates with respect to the French Franc $(\mathrm{FF} / \$)$, the German Mark $(\mathrm{DM} / \$)$, the Italian Lira (IL/\$), the Canadian Dollar $(\mathrm{CN} / \$)$, the Japanese Yen $(\mathrm{YN} / \$)$, and the British Pound $(\mathrm{BP} / \$)$. The first three exchange rates belong to the European Monetary System, while the other three do not. These rates (indirect quote) are selling rates for interbank transactions in sizes of at least one million U.S. dollars as reported in The Wall Street Journal. The period is from January 4, 1982 to November 5, 1991 for a total of 2553 observations.

The paper examines the degree of volatility persistence of the six exchange rates before and after 1985 when the U.S. dollar's world value fluctuated sharply. In particular, the period before March of 1985 was illustrated by a stunning strength in the dollar and by consequence, equal weakness of the EMS and other major currencies. This strength, attributable to economic and political reasons, resulted in an effort (known as the Plaza Agreement in late 1985) to establish a close coordination between the industrial countries. The agreement called for slowing down the dollar's slide which had already started in March and continued through all of 1986 into 1987. In February of 1987 , the same countries met again and reached a new agreement (the Louvre Accord) to realign their currencies and to peg exchange rates within a narrow range to support the falling dollar. Rising tensions, however, between the U.S., Japan, and Germany created financial panic from the dollar's 
fall and resulted in the breakdown of the Louvre Accord.

To obtain an idea about the properties of the distributions of the rates and validate the distinct character of the three periods, Table 1 presents the findings from a preliminary statistical analysis. Clearly, the insignificance of the means is evident from the third and the entire period's results. A striking observation is that the variances became much higher in the second period but decreased in the third. The empirical distributions of the rates are skewed, while leptokurtosis appears to be present during the first two periods only. Evidence about conditional heteroskedasticity is provided by the significance of the Lagrangian Multiplier (LM) statistic for most rates for all periods.

Time dependency results are mixed among the rates for the three periods. In general, according to the Ljung-Box (LB) statistic for six and twelve lags linearities are not a problem in the exchange rates, while nonlinearities are present and more pronounced in the first period, with the noted exception of the franc. The entire period's results, however, reveal a more clear pattern of such higher-order dependencies. Thus, it can be concluded that the rates are not white noise since the squared series are not realizations of strict white noise processes. Finally, two statistics for unit root are included, namely the Augmented Dickey-Fuller (ADF) and the Phillips-Perron (PP), giving evidence of absence of a unit root in the series. $^{4}$

To find the most descriptive model specification we tried with several orders of $\mathrm{p}$ and $\mathrm{q}$ and concluded that a low order configuration $(p=q=1)$ for the conditional variance was superior. $^{5}$ Table 2 reports the estimates of the EGARCH-M model for the six exchange rates for the three subperiods. Also, computations of the Half-Life of a shock and unconditional variance are included. At first glance, the significance of the volatility persistence, $a_{2}$, with its marked increase in the second period for all three EMS rates and the pound and its quelling in the third stands out. Regarding the other estimated parameters, however, there is diversity in the results among the rates across the periods.

In particular, some points are worth mentioning. First, the significance of the autoregressive coefficient, $\beta_{2}$, for the yen (and marginally for the lira, franc, and the mark) in the first period violates the martingale hypothesis, according to which future rates are not predictable from past information. This result has been documented by other authors as well (Koutmos and Theodossiou, 1993, and Koutmos, 1993) and may be due to differences inherent in these markets. Second, the coefficient $b_{3}$ that links volatility to the conditional mean, being negative for the EMS rates for the first two subperiods and positive in the third, borders statistical significance in the first period but becoming insignificant thereafter. Its importance would mean that higher volatility in a given rate is attributed to U.S. dollar depreciations (if $b_{3}$ is negative).

Third, the asymmetry coefficient g provides some mixed results. In the first period, its insignificance for the yen, franc, lira, and the mark means that only the magnitude of a shock matters (since $a_{1}$ is significant) for these rates. For the pound, it is negative and significant indicating that dollar depreciations cause higher volatility than do appreciations, whereas for the Canadian dollar depreciations cause lower volatility than do appreciations. These conclusions are proved from the results in the second period, in which volatility for the Canadian dollar has decreased and increased for the pound, following the dollar depreciation. In the second period, only the magnitude of a shock seems to be influential for all rates except for the yen. Lastly, the third period reveals that both the magnitude and the sign effect are important for all rates (except for the yen again) when a shock occurs.

Fourth, as might be expected, the HalfLife of a shock (dollar appreciation or depreciation) substantially persisted for the EMS rates and the pound in the second period with a minor reduction in the third. For the yen and the Canadian dollar, shocks became much less persistent since the dollar's depreciation in 1985. In drawing an analogy with the results of Table 1 , the insignifi- 
TABLE 1

Summary Sample Statistics
$\mathrm{CN} / \$$
$\mathrm{YN} / \$$
$\mathrm{BP} / \$$
FF/\$
IL/\$
$\mathrm{DM} / \$$

1st Subperiod: 01/04/1982 - 02/28/1985

\begin{tabular}{|c|c|c|c|c|c|c|}
\hline mean & $0.0184 *$ & 0.0216 & $-0.0704 *$ & $0.0723 *$ & $0.0677 *$ & $0.0490 *$ \\
\hline variance & 0.0667 & 0.3682 & 0.3969 & 0.5216 & 0.3949 & 0.4738 \\
\hline skewness & -0.0404 & $-0.5387 *$ & $0.4706^{*}$ & $0.2886^{*}$ & $-0.6882 *$ & $-0.7370^{*}$ \\
\hline kurtosis & $5.5294 *$ & $3.0091 *$ & $3.7720^{*}$ & $11.2632 *$ & $5.0897 *$ & $4.1982 *$ \\
\hline LM(4 lags) & $106.446 * *$ & $17.845^{* *}$ & $32.285 * *$ & 5.5526 & $41.262 * *$ & $27.0887 * *$ \\
\hline $\mathrm{LB}(6)$ & 5.4160 & 9.2760 & 5.7812 & $14.2952 *$ & 11.1972 & $14.3376 *$ \\
\hline $\mathrm{LB}(12)$ & 16.2711 & 13.5382 & 20.0700 & 19.2681 & 15.9960 & $21.0712 *$ \\
\hline $\mathrm{LB}^{2}(6)$ & $173.7842 * *$ & $31.3491 * *$ & $36.4613 * *$ & 8.4051 & $52.9401 * *$ & $44.5732^{* *}$ \\
\hline $\mathrm{LB}^{2}(12)$ & $213.4941 * *$ & $63.6632 * *$ & $41.5682 * *$ & 8.9162 & $54.2512 * *$ & $47.8253 * *$ \\
\hline $\mathrm{ADF}$ & -12.8945 & -11.3569 & -12.6935 & -11.8885 & -12.4047 & -12.4047 \\
\hline P-P & -27.4029 & -29.5716 & -29.4926 & -30.2088 & -30.6047 & -31.0666 \\
\hline
\end{tabular}

2nd Subperiod: 03/01/1985 - 11/30/1987

\begin{tabular}{|c|c|c|c|c|c|c|}
\hline mean & -0.0082 & $-0.0961 *$ & $0.0757^{*}$ & -0.0860 & $-0.0767 *$ & $-0.1012 *$ \\
\hline variance & 0.0802 & 0.4744 & 0.7234 & 0.6375 & 0.5954 & 0.6566 \\
\hline skewness & $0.4694 *$ & $-0.6994 *$ & $0.4595 *$ & $-0.5527 *$ & $-0.3390 *$ & $-0.5352 *$ \\
\hline kurtosis & $4.9538 *$ & $4.9307 *$ & $3.8085 *$ & $3.9365 *$ & $3.4064^{*}$ & $3.6289 *$ \\
\hline LM(4 lags) & $32.3048 * *$ & $66.8646^{* *}$ & $32.8408 * *$ & $16.6099 * *$ & 10.8668 & $15.7328 * *$ \\
\hline $\mathrm{LB}(6)$ & 2.4816 & $17.8485^{* *}$ & 4.1033 & 5.2527 & 3.3329 & 5.6617 \\
\hline $\mathrm{LB}(12)$ & 8.9430 & $28.5290 * *$ & 15.2224 & 18.1086 & 12.8304 & 17.1592 \\
\hline $\mathrm{LB}^{2}(6)$ & $12.9806^{*}$ & $58.5790 * *$ & $38.9977 * *$ & 8.7172 & 4.8122 & 10.2184 \\
\hline $\mathrm{LB}^{2}(12)$ & $23.2470 *$ & $65.7034 * *$ & $56.7280 * *$ & 18.6340 & 13.3966 & 21.0810 \\
\hline ADF & -12.8504 & -10.0877 & -11.7750 & -11.5177 & -11.9345 & -11.4114 \\
\hline P-P & -25.4008 & -26.2463 & -25.5719 & -26.2663 & -26.2650 & -26.2235 \\
\hline
\end{tabular}

3rd Subperiod: $12 / 01 / 1987-12 / 09 / 1991$

\begin{tabular}{|c|c|c|c|c|c|c|}
\hline mean & $-0.0139 * *$ & -0.0382 & -0.0001 & -0.0043 & -0.0038 & -0.0048 \\
\hline variance & 0.0665 & 0.4585 & 0.5195 & 0.4857 & 0.4520 & 0.5305 \\
\hline skewness & 0.2023 & -0.1050 & -0.1689 & $0.2630 *$ & $0.2554^{*}$ & $0.2857 *$ \\
\hline kurtosis & $3.2335^{*}$ & $2.8336^{*}$ & $1.4942 *$ & $1.6824 *$ & $1.7446^{*}$ & $1.9104 *$ \\
\hline LM(4 lags) & $81.2451 * *$ & $44.5008 * *$ & $14.6737 * *$ & $22.1039 * *$ & $22.6608 * *$ & $20.8561 * *$ \\
\hline $\mathrm{LB}(6)$ & 6.2007 & 7.3850 & 10.2808 & 8.9988 & 10.0097 & 7.1090 \\
\hline $\mathrm{LB}(12)$ & 12.0741 & 11.2361 & 19.0591 & 14.9101 & 17.8414 & 13.1474 \\
\hline $\operatorname{LB}^{2}(6)$ & 8.7136 & 10.0360 & $20.7924 * *$ & 8.7341 & 5.4821 & 8.8591 \\
\hline $\mathrm{LB}^{2}(12)$ & 18.7132 & $26.1568 *$ & 14.2634 & 18.7582 & 14.7062 & $21.0820 *$ \\
\hline $\mathrm{ADF}$ & -14.9283 & -14.2525 & -13.3701 & -13.7924 & -13.7832 & -13.9283 \\
\hline P-P & -33.9461 & -33.2475 & -32.4718 & -34.2476 & -34.0483 & -33.9461 \\
\hline \multicolumn{7}{|c|}{ Entire period: $01 / 04 / 1982-12 / 09 / 1991$} \\
\hline mean & -0.0016 & -0.0207 & -0.0026 & -0.0019 & 0.0002 & -0.0134 \\
\hline variance & 0.0707 & 0.4362 & 0.5411 & 0.5426 & 0.4764 & 0.5506 \\
\hline skewness & $0.2190 *$ & $-0.4155^{*}$ & $0.2776^{*}$ & -0.0399 & $-0.2423 *$ & $-0.3039 *$ \\
\hline kurtosis & $4.4826^{*}$ & $3.6299 *$ & $3.2788^{*}$ & $5.4931 *$ & $3.2761 *$ & $3.2005 *$ \\
\hline LM(4 lags) & $182.7548 * *$ & $136.9454 * *$ & $91.9042 * *$ & $35.7822 * *$ & $67.8564 * *$ & $61.457 * *$ \\
\hline $\mathrm{LB}(6)$ & 5.4096 & $21.5619 * *$ & 6.1713 & 9.8989 & 4.0418 & 6.9559 \\
\hline $\mathrm{LB}(12)$ & 18.1148 & $29.1340 * *$ & 14.9790 & $22.4792 *$ & 13.6556 & 17.4729 \\
\hline $\mathrm{LB}^{2}(6)$ & $90.7631 * *$ & $146.5451^{* * *}$ & $110.7579 * *$ & $59.9938 * *$ & $93.387 * *$ & $97.535 * *$ \\
\hline $\mathrm{LB}^{2}(12)$ & $114.3679 * *$ & $171.3474 * *$ & $143.9318 * *$ & $73.7080 * *$ & $110.250 * *$ & $115.957 * *$ \\
\hline $\mathrm{ADF}$ & -12.7899 & -12.3261 & -12.4325 & -11.6721 & -12.4351 & -12.4309 \\
\hline P-P & -28.5362 & -26.8217 & -26.8256 & -27.7819 & -26.8136 & -28.3627 \\
\hline
\end{tabular}

Notes: the series are in logarithmic changes; $\$=U$.S. dollar; $C N=$ Canadian dollar; $F F=$ French Franc; DM=Deutsche Mark; $\mathrm{IL}=$ Italian Lira; $Y N=$ Japanese Yen; $\mathrm{BP}=$ British Pound; ADF=Augmented Dickey Fuller for unit root tests (up to 4 lags); $\mathrm{P}$ $\mathrm{P}=$ Phillips-Perron, also for unit root tests (up to 4 lags); $\mathrm{LB}(\mathrm{n})=$ Ljung-Box with $\mathrm{n}$ lags; the $\mathrm{LB}$ critical values for six lags are 12.592 and 16.812 for the five and the one percent levels, respectively, and for twelve lags with the same significance levels 21.026 and 26.217; the LM critical values are 9.488 for five percent and 13.277 for the one percent level of significance; finally, the ADF and P-P critical values are $-1.995,-2.864$ for the one and five percent levels, respectively; $*, * *$ mean significance at the 5 and 1 percent levels, respectively. 


\begin{tabular}{|c|c|c|c|c|c|c|}
\hline \multicolumn{7}{|c|}{$\begin{array}{c}\text { TABLE } 2 \\
\text { Exponential Garch-M Estimates }\end{array}$} \\
\hline Estimates & $\mathrm{CN} / \$$ & $\mathrm{YN} / \$$ & $\mathrm{BP} / \$$ & $\mathrm{FF} / \$$ & $\mathrm{IL} / \$$ & $\mathrm{DM} / \$$ \\
\hline \multicolumn{7}{|c|}{ 1st Subperiod: 01/04/1982 - 02/28/1985 (704 obs.) } \\
\hline \multirow{2}{*}{$b_{1}$} & 0.0304 & 0.0873 & -0.0047 & -0.0018 & 0.0061 & -0.0412 \\
\hline & $(0.0299)$ & $(0.1336)$ & $(0.0662)$ & $(0.0541)$ & $(0.0598)$ & $(0.0589)$ \\
\hline \multirow{2}{*}{$b_{2}$} & -0.0419 & $-0.1509 * *$ & -0.0067 & $-0.0873^{*}$ & $-0.0821 *$ & $-0.0800 *$ \\
\hline & $(0.0345)$ & $(0.0337)$ & $(0.0388)$ & $(0.0365)$ & $(0.0367)$ & $(0.0400)$ \\
\hline \multirow[t]{2}{*}{$b_{3}$} & 0.0033 & 0.0924 & 0.1502 & -0.1646 & -0.1337 & $-0.2227 *$ \\
\hline & $(0.0153)$ & $(0.2635)$ & $(0.1082)$ & $(0.0891)$ & $(0.0860)$ & $(0.0993)$ \\
\hline \multirow[t]{2}{*}{$a_{0}$} & -0.0387 & 0.0180 & $-0.0895 * *$ & $-0.0414 * *$ & $-0.0844 * *$ & $-0.0598^{*}$ \\
\hline & $(0.0212)$ & $(0.0460)$ & $(0.0311)$ & $(0.0144)$ & $(0.0315)$ & $(0.0238)$ \\
\hline$a_{1}$ & $\begin{array}{l}0.1737^{* *} \\
(0.0281)\end{array}$ & 0.0003 & $0.2820 * *$ & $0.3727^{*} *$ & $0.3567 * *$ & $0.3221 * *$ \\
\hline \multirow{2}{*}{$a_{2}$} & $\begin{array}{l}(0.0281) \\
0.9848 * *\end{array}$ & $\begin{array}{l}(0.0033) \\
0.9800 * *\end{array}$ & $\begin{array}{l}(0.0431) \\
0.9037 * *\end{array}$ & $\begin{array}{l}(0.0497) \\
0.9321 * *\end{array}$ & $\begin{array}{l}(0.0504) \\
0.0173 * *\end{array}$ & $(0.0493)$ \\
\hline & $(0.0064)$ & $(0.0048)$ & $(0.0292)$ & $(0.0188)$ & $(0.0259)$ & $(0.0231)$ \\
\hline \multirow[t]{2}{*}{ g } & $0.6993 * *$ & 18.5800 & $-0.2095^{*}$ & 0.1222 & 0.1112 & 0.0987 \\
\hline & $(0.1543)$ & $(19.975)$ & $(0.0861)$ & $(0.0768)$ & $(0.0733)$ & $(0.0750)$ \\
\hline HL & 45.2750 & 34.3118 & 6.8481 & 9.8592 & 8.0314 & 9.1803 \\
\hline UV & 0.0768 & 0.4065 & 0.3948 & 0.5435 & 0.3665 & 0.4400 \\
\hline $\mathrm{L}(\mathrm{X})$ & -84.3440 & -90.785 & -30.672 & -76.808 & -38.152 & -47.175 \\
\hline \multicolumn{7}{|c|}{ 2nd Subperiod: 03/01/1985 - 11/30/1987 (814 obs.) } \\
\hline$b_{1}$ & 0.0778 & 0.2606 & 0.0778 & $-0.1422 * *$ & $-0.1226^{*}$ & $-0.1677 * *$ \\
\hline & $(0.0531)$ & $(0.2717)$ & $(0.0531)$ & $(0.0528)$ & $(0.0520)$ & $(0.0512)$ \\
\hline$b_{2}$ & 0.0374 & 0.0148 & 0.0374 & -0.0143 & 0.0124 & 0.0066 \\
\hline \multirow{2}{*}{$b_{3}$} & 0.0504 & $\begin{array}{l}(0.0405) \\
1.0731\end{array}$ & $\begin{array}{c}(0.0381) \\
0.0504\end{array}$ & $\begin{array}{l}(0.0477) \\
-0.1402\end{array}$ & $\begin{array}{l}(0.0422) \\
-0.1320\end{array}$ & $(0.0421)$ \\
\hline & $(0.1108)$ & $(0.7950)$ & $(0.1108)$ & $(0.1020)$ & $(0.1032)$ & $\begin{array}{l}-0.1644 \\
(0.1113)\end{array}$ \\
\hline \multirow[t]{2}{*}{$\mathrm{a}_{0}$} & -0.0070 & -0.0015 & -0.0070 & -0.0198 & -0.0249 & -0.0197 \\
\hline & $(0.0064)$ & $(0.0050)$ & $(0.0064)$ & (0.0107) & $(0.0146)$ & $(0.0119)$ \\
\hline \multirow[t]{2}{*}{$a_{1}$} & $0.2011 * *$ & -0.0058 & $0.2011^{*} *$ & $0.2484 * *$ & $0.2421 * *$ & $0.2360 * *$ \\
\hline & $(0.0289)$ & $(0.0041)$ & $(0.0289)$ & $(0.0559)$ & $(0.0548)$ & $(0.0565)$ \\
\hline$a_{2}$ & $\begin{array}{l}0.9724 * * \\
(0.0090)\end{array}$ & $0.9890 * *$ & $0.9724 * *$ & $0.9604 * *$ & $0.9560 * *$ & $0.9556^{* * *}$ \\
\hline \multirow[t]{2}{*}{ g } & 0.0640 & $\begin{array}{c}(0.0078) \\
1.3360\end{array}$ & $\begin{array}{c}(0.0090) \\
0.0640\end{array}$ & $\begin{array}{c}(0.010 /) \\
0.1184\end{array}$ & $\begin{array}{c}(0.0211) \\
0.1380\end{array}$ & $\begin{array}{c}(0.0194) \\
0.0567\end{array}$ \\
\hline & $(0.0895)$ & $(0.8292)$ & $(0.0895)$ & $(0.1106)$ & $(0.1214)$ & $(0.1141)$ \\
\hline HL & 24.8401 & 63.0010 & 24.8420 & 17.1563 & 15.4024 & 15.2669 \\
\hline UV & 0.7759 & 0.8725 & 0.7759 & 0.6065 & 0.5678 & 0.6416 \\
\hline $\mathrm{L}(\mathrm{X})$ & -160.852 & -88.418 & -150.878 & -142.638 & -125.849 & -163.940 \\
\hline \multicolumn{7}{|c|}{ 3rd Subperiod: 12/01/1987 - 12/09/1991 (1030 obs.) } \\
\hline$b_{1}$ & -0.0470 & 0.0383 & -0.1065 & 0.0023 & 0.0012 & 0.0137 \\
\hline & $(0.0402)$ & $(0.0493)$ & $(0.0627)$ & $(0.0618)$ & $(0.0651)$ & $(0.0628)$ \\
\hline$b_{2}$ & -0.0305 & -0.0184 & -0.0077 & -0.0495 & -0.0498 & -0.0430 \\
\hline & $\begin{array}{l}(0.0315) \\
-0.0220\end{array}$ & $(0.0346)$ & $\begin{array}{l}(0.0323) \\
-02837 *\end{array}$ & $(0.0339)$ & $(0.0332)$ & $(0.0334)$ \\
\hline$b_{3}$ & $\begin{array}{l}-0.0220 \\
(0.0128)\end{array}$ & $\begin{array}{c}0.0646 \\
(0.0834)\end{array}$ & $\begin{array}{l}-0.2837^{*} \\
(0.1385)\end{array}$ & 0.0078 & 0.0056 & 0.0455 \\
\hline$a_{0}$ & $-0.1086^{* *}$ & -0.0367 & $-0.0363 * *$ & $-0.0308^{*}$ & $\begin{array}{l}(0.1209) \\
-0.0313^{*}\end{array}$ & $\begin{array}{l}(0.1478) \\
-0.0257 *\end{array}$ \\
\hline & $(0.0240)$ & $(0.0128)$ & $(0.0118)$ & $(0.0121)$ & $(0.0131)$ & $(0.0110)$ \\
\hline$a_{1}$ & $0.1900^{* *}$ & $0.2178 * *$ & $0.1320 * *$ & $0.1352 * *$ & $0.1276 * *$ & $0.1234 * *$ \\
\hline & $(0.0275)$ & $(0.0266)$ & $(0.0314)$ & $(0.0296)$ & $(0.0289)$ & $(0.0288)$ \\
\hline$a_{2}$ & $0.9580 * *$ & $0.9468^{* *}$ & $0.9422 * *$ & $0.9521 * *$ & $0.9588^{*} *$ & $0.9555 * *$ \\
\hline & $(0.0084)$ & $(0.0135)$ & $(0.0169)$ & $(0.0152)$ & $(0.0147)$ & $(0.0158)$ \\
\hline $\mathrm{g}$ & $\begin{array}{r}0.2182 * \\
(0.0972)\end{array}$ & -0.0314 & $-0.5610 * *$ & $0.3877 * *$ & $0.3660 * *$ & $0.3897 * *$ \\
\hline $\mathrm{HL}$ & 16.1563 & 12.6940 & 11.6482 & 14.1440 & $\begin{array}{l}(0.1201) \\
16.5023\end{array}$ & $\begin{array}{l}(0.1400) \\
15.2321\end{array}$ \\
\hline UV & 0.0753 & 0.5016 & 0.5336 & 0.5257 & 0.4678 & 0.5625 \\
\hline $\mathrm{L}(\mathrm{X})$ & -940.527 & -56.2950 & -148.475 & -111.018 & -57.494 & -152.106 \\
\hline
\end{tabular}


cance of the means is consistent with the earlier findings and the unconditional variances are strikingly similar to their corresponding sample counterparts, corroborating thus the suitability of the EGARCH-M model in modeling exchange rate volatility and asymmetric behavior.

As a final check for the appropriateness of our model, it is instructive to perform some residual diagnostic tests the results of which are tabulated in Table 3. The standardized residuals for all exchange rates have zero mean and unit variance. The estimated empirical model accounts for a large percentage of the skewness and kurtosis of the rates, while the Kolmogorov-Smirnov Dstatistic for normality check presents no serious evidence of deviations from it. Further, the Lagrangian Multiplier statistic accepts the homoskedasticity hypothesis in the residuals for up to four lags. Finally, the Ljung-Box statistics (up to six lags) for the standardized and squared residuals are insignificant for some exchange rates but the possibility of higher-order dependencies cannot be completely ruled out for the rest.

\section{Summary And Conclusions}

In this paper the behavior of volatility of six major exchange rates (three EMS, namely French franc, Italian lira, and German mark and three non-EMS, the Canadian dollar, the British pound, and the Japanese yen) under the asymmetric cycle of the U.S. dollar, that is, before and after 1985 was investigated. The analysis of daily data confirmed the usual properties of short-run dynamics like dependence of volatility, heteroskedasticity, and highly leptokurtic distributions. The Exponential GARCH model seems to be effective in modeling the changing volatility of the six exchange rates as residual diagnostics showed. The study was based on three periods in the history of the dollar, which appeared to have a distinct effect on the pattern of the exchange rates volatility.

During the first period (1982-1985), the violation of the martingale hypothesis implies that predictability of volatility was possible from past information for the EMS rates and the yen. High persistence of volatility, being especially pronounced for the Canadian dollar and the yen, also characterized the period of dollar appreciation. The second period (1985-1987), associated with dollar depreciation, witnessed a striking increase in the stochastic variance (volatility) in the EMS rates and the pound, with no noticeable change in that of the yen's. This result appears to dispute the efficient markets hypothesis and may have serious speculative effects. The third period (1987-1991), also identified by a falling dollar, saw a reduction in volatility in the non-EMS but not in the EMS exchange rates and, most notably, the asymmetry coefficient reveals that dollar depreciations increased, or at least kept high, the volatility more than dollar appreciations did.

The dollar's strong influence in the international financial markets and its domination by capital movements, which vary quickly in response to changing expectations or confidence, make the exchange rate of the dollar volatile and highly unpredictable. Thus, later in the 1980s, the unprecedented plunge in the dollar's value necessitated a huge volume of foreign exchange trading as investors struggled to preserve the value of their global investments. This situation, evidently, created more uncertainty in the dollar's future and hence greater exchange rate volatility. The coordinated efforts of several major banks during that six-year period resulted in a failure to stabilize the markets and therefore had no perceptible impact on the exchange rate volatilities. ${ }^{6}$

This asymmetric nature of volatility of the EMS and non-EMS exchange rates, following a U.S. dollar appreciation or depreciation, should be exploited by financial analysts when developing models for the pricing of derivative securities that use volatility estimates. Hence, once again, the substantial influence of the U.S. dollar on the exchange rates could be due to the fact that there is uncertainty in a weak dollar's future, mostly because of political reasons, and that tends to exacerbate volatility in the exchange rates. ${ }^{7}$

\section{Suggestions For Future Research}

A useful application of the EGARCH model is the study of the time-varying risk premia in interest or eurocurrency rates. Also, by adjusting the conditional variance one can examine the 


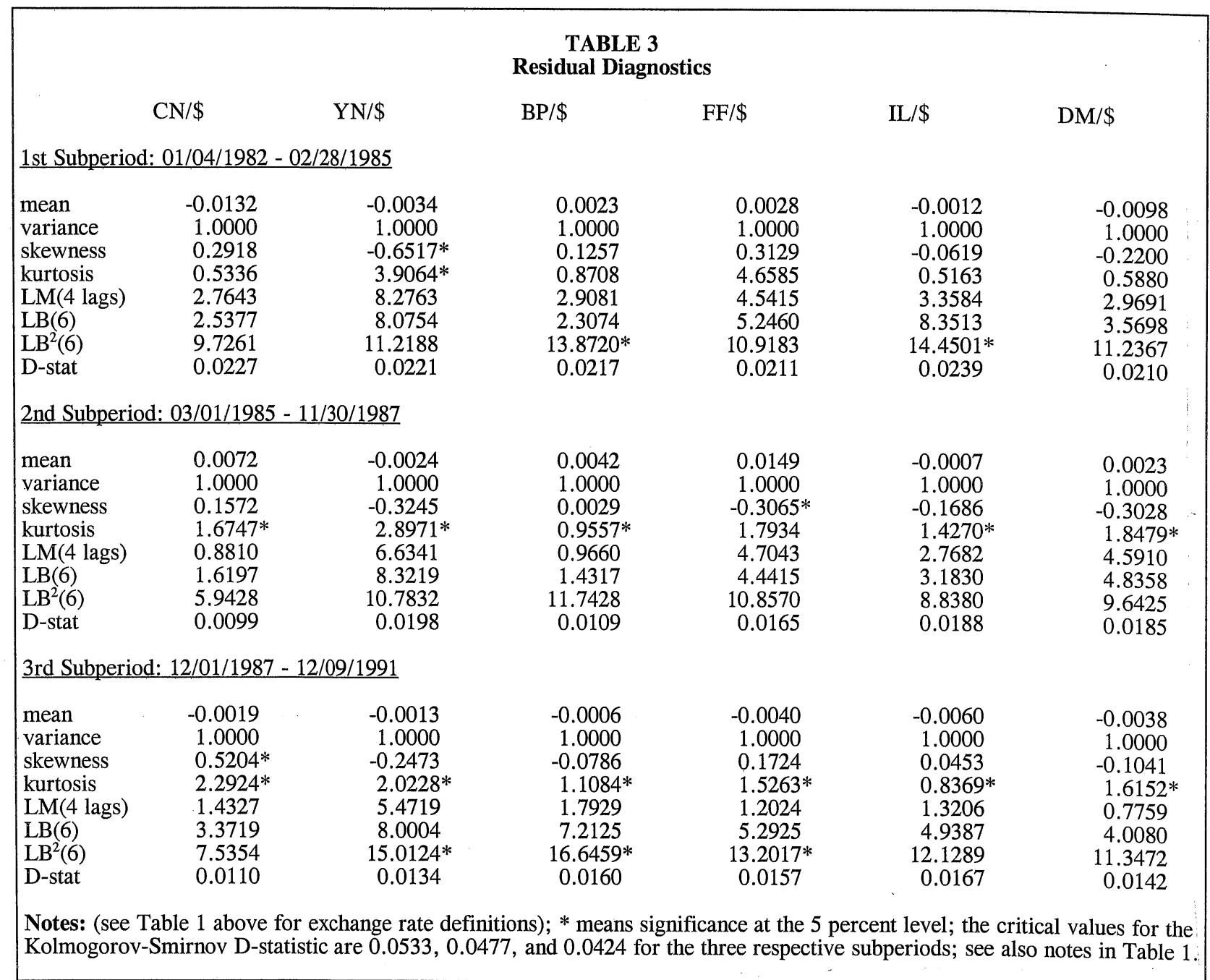

extent to which the forward premium influences exchange rate volatility.

\section{Endnotes}

1. See the studies of McCurdy and Morgan (1988), Hsieh (1989), Bollerslev (1990), Akgiray and Booth (1991), Kaehler (1991), Koutmos and Theodossiou (1993).

2. For instance Baillie and Bollerslev (1990).

3. Pagan and Schwert (1990), Nelson (1991), Koutmos (1992) among others.

4. The Augmented Dickey-Fuller (ADF) test involves estimating the following model: $y_{t}$ $=\mathrm{a}_{0}+\mathrm{a}_{1} \mathrm{t}+\mathrm{a}_{2} \mathrm{~S}_{\mathrm{t}-1}+\mathrm{Sc}_{\mathrm{s}} \mathrm{y}_{\mathrm{t}-\mathrm{s}}+\mathrm{u}_{\mathrm{t}}$ and testing the null $\mathrm{H}_{0}: \mathrm{a}_{2}=0$ versus the alternative $H_{a}: a_{2}<0$, where $S_{t}=\log \left(S_{t}\right), S_{t}$ is the exchange rate, $y_{t}=S_{t}-S_{t-1}$, and $t$ a trend variable. See Dickey and Fuller, 1979) for details. The Phillips-Perron (PP) test is done by means of estimating the following model: $S_{t}=b_{0}+b_{1}(t-T / 2)+b_{2} S_{t-1}+v_{t}$ and testing the null $\mathrm{H}_{0}: \mathrm{b}_{2}=1$ versus the alternative $\mathrm{H}_{\mathrm{a}}: \mathrm{b}_{2}<1$, where $\mathrm{T}$ is the sample size. See Phillips and Perron (1988) for details. Acceptance of the $\mathrm{H}_{0}$ implies presence of a unit root in the $S_{t}$ series.

5. A low-order specification has been documented by others like Baillie and McMahon (1989), Baillie and Bollerslev (1989), and Koutmos and Theodossiou (1994).

6. A number of studies studied the effects of central bank intervention during this period such as Baillie and Humpage (1992), Dominguez (1993), and Bonser-Neal (1996). Their results were mixed as to the success or failure of such intervention attempts. 
7. See Koutmos (1994).

\section{References}

1. Akgiray, V. and Booth G.C, "Modeling the Stochastic Behavior of Canadian Foreign Exchange Rates," Journal of Multinational Financial Management, 1, pp. 43-71, 1991.

2. Baillie, R.T. and Bollerslev, T., "The Message in Daily Exchange Rates: A Conditional Variance Tale," Journal of Business and Economic Statistics, 7, pp. 297-305, 1989.

3. Baillie, R.T. and McMahon, P.C., The Foreign Exchange Market: Theory and Econometric Evidence, Cambridge University Press, Cambridge, 1989.

4. Baillie, R.T. and Humpage, O., "PostLouvre Intervention: Did Target Zones Stabilize the Dollar?" Federal Reserve Bank of Cleveland, working paper no. 9203, 1992.

5. Berndt, E.K., Hall, H.B., Hall, R.E., and Hausman, J.A., "Estimation and Inference in Nonlinear Structural Models," Annals of Economic and Social Measurement, 4, October, pp. 653-666, 1974.

6. Bollerslev, T., "Generalized Autoregressive Conditional Heteroskedasticity," Journal of Econometrics, 31, pp. 307-327, 1986.

7. Bollerslev, T., Chou, R.Y., and Kroner, K.F., "ARCH Modeling in Finance: A review of the Theory and Empirical Evidence," Journal of Econometrics, 52, pp. 559, 1992.

8. Bonser-Neal, C., "Does Central Bank Intervention Stabilize Foreign Exchange Rates?" Federal Reserve Bank of Kansas City Economic Review, Vol. 1, No. 81, 1996.

9. Dickey, D.A. and Fuller, W.A., "Distribution of the Estimates for Autoregressive Time Series with Unit Root." Journal of the American Statistical Association, 74, June, pp. 427-32, 1979.

10. Dominguez, C., "Does Central Bank Intervention Increase the Volatility of Foreign Exchange Rates?" National Bureau of Economic Research working paper no. 4532, 1993.

11. Engle, R.F., "Autoregressive Conditional
Heteroskedasticity with Estimates of the Variance of U.K. Inflation." Econometrica, 50, pp. 987-1008, 1982.

12. Hsieh, D., "Modeling Heteroskedasticity in Daily Foreign Exchange ates," Journal of Business and Economic Statistics, 7, pp. 307-317, 1989.

13. Keahler, J., "Modelling and Forecasting Exchange-Rate Volatility with ARCH-Type Models," Discussion paper No. 91-02, Zentrum Fur Europaische WirtschaftsForschung, Mannheim, Germany, 1991.

14. Koutmos, G., "Asymmetric Volatility and Risk-Return Tradeoff in Foreign Stock Markets," Journal of Multinational Financial Management, 2, pp. 27-43, 1992.

15. _ "Exchange Rate Volatility During Appreciations and Depreciations," Journal of Midwest Finance Association, 22, pp. 1523, 1993.

16. Koutmos, G. and Theodossiou, P., "TimeSeries Properties and Predictability of Greek Exchange Rates," Managerial and Decision Economics, 1993.

17. McCurdy, T.H. and Morgan, I., "Testing the Martingale Hypothesis in Deutsche Mark Futures with Models Specifying the Form of the Heteroskedasticity," Journal of Applied Econometrics, 3, pp. 187-202, 1988.

18. Nelson, D., "Conditional Heteroskedasticity in Asset Returns: A New Approach," Econometrica, 59, pp. 347-370, 1991.

19. Pagan, A. and Schwert, G., "Alternative Models for Conditional Stock Volatility," Journal of Econometrics, 45, pp. 267-290, 1990.

20. Phillips, P.C.B. and Perron, P., "Testing for a Unit Root in Time Series Regression," Biometrika, 75, pp. 335-346, 1988. 